\title{
Intensifications reactive power during of asymmetric network outages in dual-stator winding generators
}

\author{
Qasim Al Azze, Balasim M. Hussein, Hayder Salim Hameed \\ Department of Electrical Power \& Machine Engineering, College of Engineering, University of Diyala, Baquba, Diyala, \\ Iraq
}

\begin{tabular}{l} 
Article Info \\
\hline Article history: \\
Received Apr 8, 2021 \\
Revised Sep 14, 2021 \\
Accepted Sep 21, 2021 \\
\hline
\end{tabular}

Keywords:

Asymmetrical fault Brushless dual-stator winding reluctance generator Low voltage ride through Stator-field oriented control Wind turbine

\begin{abstract}
The paper proposes a protection to dual stator generator, reluctance rotor, from asymmetrical fault. This prevents the dual stator generator, reluctance rotor, from electrical sage through the working process in order to avoid any interruption in the generator-grid connection. The procedure was consummated by injecting suitable reactive power during the fault period. The proposed method makes it possible for wind turbine application via dual stator winding generators (DSWRG) synchronous mod to stay connected to the grid during asymmetrical faults. It has been built according to trusted simulating mode considering all tested parameters according to experiment work. The experiment, consider the DC link side stability and care about the behavior and performance of machine side parameter. As well the machineability is evaluated to ride through asymmetrical fault by observing the secondary side current which has a big role in saving grid side converter. The control takes a response within $200 \mathrm{~ms}$ after fault trigger recognition. The generator's ability to dynamically remaining connected stable and existing in the network, which is sustained a series voltage disturbance by injecting an appropriate amount of reactive power. The main interest required in this paper is the capability of a machine to overcome the asymmetrical fault.
\end{abstract}

This is an open access article under the CC BY-SA license.

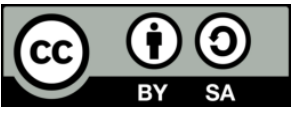

Corresponding Author:

Qasim Al Azze

Department of Electrical Power and Machine Engineering

College of Engineering, University of Diyala

Baquba, Diyala, Iraq

Email: alazzeqasim@gmail.com

\section{INTRODUCTION}

The impact of escalation wind farms penetrating due to the remarkable success in supporting green clean energy during the recent years provided serious cooperation with different resources to achieve an integrated and stable power generation system [1]-[3]. The urgent need for a reliable protection system to protect (turbo generators) from the potential symmetrical and asymmetrical fault that occurs in the distribution network become under the process of study and evaluations [4], [5]. That inflicts new requirements to ensure the quality energy distribution named grid code requirements [6]. The code of the grid states winds generator capability to promoter power system [7] thru powering auxiliary services like control of voltage and secure, reliable, and safe operations of the power system. Power electronics are the promoting technology still practical solutions for grid interfacing of wind turbines with the grid requirements [8]-[10].

Due to green electrical power needs worldwide, they start to build large wind power farms such as Thant's offshore wind turbine farms in the UK. Accordingly, all renewable energy requires to connect to the network of the power system. Therefore, the connection between the existing wind power generators and the 
Network distribution stability becomes a concerning issue. Even that, most wind generators are suddenly disconnected from the grid in fault situations the performance of the power system distribution becomes unstable. That considers the greatest problem of integrating wind generators into the grid [11]. That's enlightening on the quality of the energy correlated with the traditional wind generators, which require an extended time to return to the previous stable performance again [12]-[14].

Then, under this case, there is an idea to compensate suitable rechargeable power for probable shortterm asymmetrical fault by adopting new system requirements [15]. The trusted MATLAB software simulation model has been done to enable this study to take into account the grid side machine performance and evaluate the machine's ability to ride through an asymmetrical disturbance. The observing of both side stator windings has a major role in providing the grid side fluctuations during short term fault and evaluate the machine behaviors through it [16].

\section{PROBLEM STATEMENT}

The asymmetrical fault does not affect each of the three phases of primary voltages equally. This study deals with temporary, and short-term period duration fault, not with permanent fault. The fault commonly happens in outdoor networks, not in the underground distribution system. The wind power generation is the most system affected by this fault which is considered less harmful than 3 phase dip voltage or (symmetrical fault) as it is named. This study started with the case of drop voltage to zero in one of three phases (first Phase). The same circumstance of the simulation software, control algorithm, and machine parameters for the $2 \mathrm{MW}$ machine which was involved in analyzing full drop voltage (symmetrical fault) in BDSRG, but with symmetrical fault condition. Asymmetrical low voltage rides through confirming the capability of the BDSRG to overcome the disturbance voltage when one phase of the 3 phases of the grid supplies dropped down and the ability of the machine to handle the fault duration impact with adopting a suitable amount of reactive power.

A brushless dual-stator winding reluctance generator (BDSWRG) with a silence rotor is one the machine has inherited save mode to protect the converter from over current and voltage disturbance (save mode) [17] as shown in Figure 1 is make this emerging machine more attractive compared with another Brushless Dual stator induction machine (BDSIM) wounded rotor [18]. BDSWRG is free maintenance, brushless design, higher reliability in comparison with other brush machines. Moreover, it can run in varied modes of operation. Such as Synchronous Machine, Indication Machine, and Doubly Excited Indication Machine. Therefore, the machine becomes very interesting for further modeling consideration. Unique and unwound rotor structure, earn it new characteristic for the specification. The owing of low leakage inductance comparing with other generators models, the ability to tolerate, such as induction machine (safe mode) improves a property of this machine, to the self-protect inverter circuit. Which considers mainly significant benefits that can be derived from this machine [19].

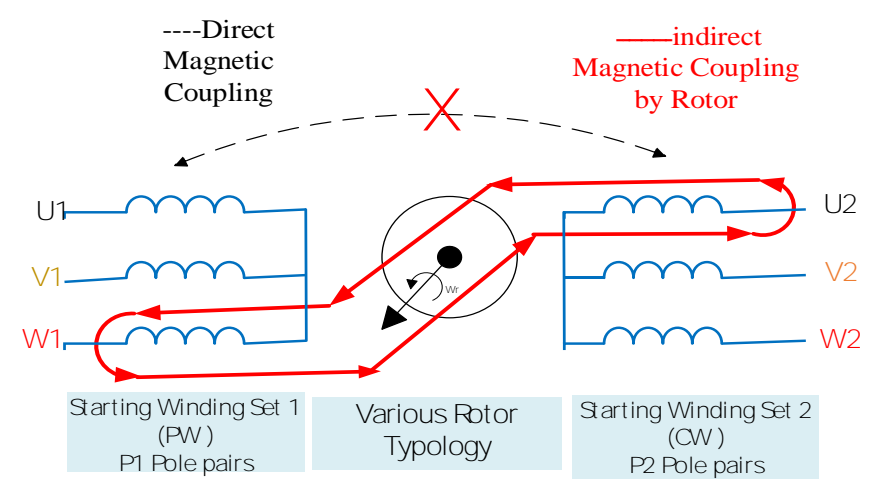

Figure 1. Turn-on and turn-off of the sr switch

\section{PROPOSED SOLUTION (RESEARCH METHOD)}

\subsection{Asymmetrical control methodology}

The stator-field oriented control (SFOC) is achieved approximately decouple Active Power and Reactive Power as well special trend to design PI regulators. Active power can be directed by control winding $(\mathrm{CW})$ as the first branch and $\mathrm{q}$-axis current. Whereas, reactive power is directed by d-axis 
component. Cross coupling between current component ( $\mathrm{q}-\mathrm{d}$ component), in the outer power-speed loop, that introduced by resistance effects of the rotor was compensated and addressed in both axis by PI regulator in [20]. This is considering a complementary attempt to test the validity and efficiency of BDSWRG to Ride Through asymmetric disturbance, after their marked efficiency to ride through the symmetric drop voltages [21]. While the superiority of the control algorithm has been derived to prevent power line outage through this short-term fault between grid-generator, by compensating suitable reactive power and dispensing the common crowbar circuits [22]. The reactive power compensating to the grid is one of the low voltage ridethrough (LVRTH) requirements to avoid the drop-in voltage through fault occurrence [23]. Therefore, the establishing trigger fault command estimator model for estimating reactive power should take into account the essential dynamic model d-q equation of the excited doubly stator winding reluctance machine, Figure 2 shows control algorithm configuration as well exited trigger fault command of the machine, the following equations are dynamic model d-q of DSWRG [24].

$$
\begin{aligned}
& U_{p d}=R_{p} i_{p d}+\frac{d \psi_{p d}}{d t}-\omega_{p} \psi_{p q} \\
& U_{p q}=R_{p} i_{p q}+\frac{d \Psi_{p q}}{d t}+\omega_{p} \psi_{p d}
\end{aligned}
$$

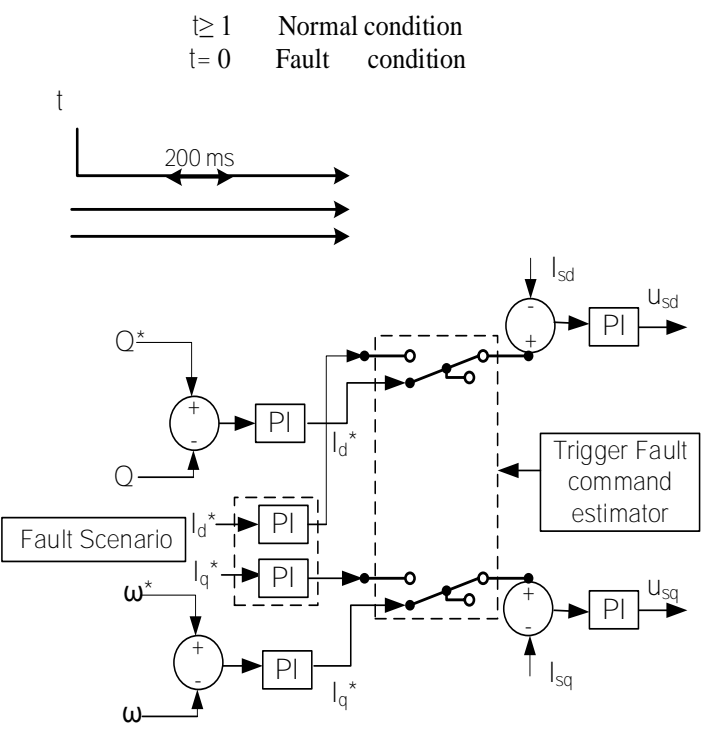

Figure 2. Configuration of control algorithm and exited trigger fault command

The reactive power loop can be identified according to the convention equation starting from the primary side as source power:

$$
\mathrm{QP}=3 / 2(\mathrm{Upq} \text { ipd }-\mathrm{Upd} \text { ipq) }
$$

Substituting (1) and (2) in (3) and solve it mathematically can gain more options to simplify.

$$
\left.Q_{p}=\frac{3}{2}[\underbrace{\left(R_{p} i_{p q}+\frac{d \psi_{p q}}{d t}+\omega_{p} \psi_{p d}\right)}_{U_{p q}} i_{p d}-\underbrace{\left(R_{p} i_{p d}+\frac{d \psi_{p d}}{d t}-\omega_{p} \psi_{p q}\right.}_{U_{p d}}) i_{p q}\right]
$$

By taking into account steady-state case $\mathrm{i}_{\mathrm{pd}}=0$.

$$
\mathrm{Q}_{\mathrm{p}}=\frac{3}{2}\left(\omega_{\mathrm{p}} \psi_{\mathrm{pd}} \mathrm{i}_{\mathrm{pd}}+\omega_{\mathrm{p}} \psi_{\mathrm{pq}}\right)
$$

Satisfying the magnitude of the primary side $\psi_{\mathrm{pd}}=\left|\psi_{\mathrm{p}}\right|$. 
$\Psi_{\mathrm{pq}}=0$ The reactive power will minimize requirements to be contingent only with:

$$
\mathrm{Q}_{\mathrm{p}}=\frac{3}{2} \omega_{\mathrm{p}} \psi_{\mathrm{pd}} \mathrm{i}_{\mathrm{pd}}
$$

Hence the linear relation exists between primary current iPd and reactive power; the loop of reactive power can be drawn as:

$$
\mathrm{i}_{\mathrm{sd}}^{*}=\mathrm{i}_{\mathrm{pd}}=\operatorname{PI}\left(\mathrm{Q}^{*}-\mathrm{Q}\right)
$$

when the Ipd serve as a main proportional variable in the (isd*) estimated currents equation, that estimated (isd*), in the first stage controller. Faults give rise to unsymmetrical currents (current differ in according to the stator field-oriented control (SFOC) hypotheses alignment $\lambda \mathrm{pq}=0$.

$$
\mathrm{T}_{\mathrm{e}}=\frac{3 \mathrm{P}_{\mathrm{r}} \mathrm{L}_{\mathrm{m}}}{2 \mathrm{~L}_{\mathrm{p}}} \psi_{\mathrm{pd}} \mathrm{i}_{\mathrm{sq}}
$$

This proves of the analogy relationship between, speed and secondary current basis torque expression.

$$
\mathrm{i}_{\mathrm{sq}}^{*}=\mathrm{PI}\left(\omega_{\mathrm{r}}^{*}-\omega_{\mathrm{r}}\right)
$$

With the presence of secondary side machine currents $i_{s d}$, $i_{s q}$ and the reference current which derived in the circumstances of a fault condition in $(7,9)$ the second stage of stator field-oriented control strategy will be developed to match:

$$
\begin{aligned}
& u_{s d=}^{*} \text { PI }\left(\mathrm{i}_{\mathrm{sd}}^{*}-\mathrm{i}_{\mathrm{sd}}\right) \\
& u_{s q}^{*} \mathrm{PI}\left(\mathrm{i}_{\mathrm{sq}}^{*}-\mathrm{i}_{\mathrm{sq}}\right)
\end{aligned}
$$

Actually, the inner loop (7), of flux-oriented control is quite similar to the voltage-oriented control. It is building his performance on the amount of the reference currents $i_{s d}{ }^{*}, i_{s q}{ }^{*}$ is obtained from the first stage and through the unit compensation PI brought up to the appropriate voltage $\mathrm{U}_{\mathrm{sd}}, \mathrm{U}_{\mathrm{sq}}$. The $\mathrm{U}_{\mathrm{sd}}, \mathrm{U}_{\mathrm{sq}}$ control voltages were established in order to build the appropriate voltage for insulated-gate bipolar transistor inverter gates. On the other hand, depending on secondary voltages, the PI controller in this control algorithm became one of the rations requirements; the stator field-oriented control relied on outside loop speed indicate of axis rotation and encoded data to be integrated with a variable speed that responds to the dynamics of rotor generator rotation performance impact in addition to the fault challenge [25]-[27]. It produces encoder data and $i_{s q}$ reactive current. The active energy gained from the primary lateral device is that open-loop data can be injected into the natural and fault control system as well. It was developed for the convenience of the appropriate voltage input to reverse the insulated-gate bipolar transistor for the production of secondary voltages supplied to the lateral control machine [28]. In this control algorithm, SFOC adopts a loop of speed to reflect the impact of the performance machine as well as the challenge of failure. The evolution of the rotary machine in torque reflects the expected action of the laboratory when the machine's rotation has evolved in the encoded data based on the reference frame and the dynamic current that respects the torque [29]. The active energy gained from the primary side device is that the open-loop data can be injected into the normal and disturbance control system conditions as well [30].

\section{RESULTS AND DISCUSSION}

2 MW BDSRG grid-connected supplied by 690 volts, DC voltage 1000 voltage depending on trusted parameters illustrated in Table 1 this simulation describes the performance generator facing short term drop or missing phase voltage for duration $200 \mathrm{~ms}$ the fault condition defers from the symmetrical an approach that it occurs in one or 2 phase not in all phases.

$$
U_{c}=\left\{\begin{array}{c}
v_{a}=0 \\
v_{b}=V_{r} \cos \left(2 \pi f . t-\frac{2 \pi}{3}\right) \\
v_{c}=V_{r} \cos \left(2 \pi f . t+\frac{2 \pi}{3}\right)
\end{array}\right.
$$


The single-phase drop considers asymmetrical nature's fault which the grid suffers under ionizations condition or temporary phase contact in outdoor distribution networks. The duration of the fault which was adopted in this research is $200 \mathrm{~ms}$ according to the EON standard. So, it requires from trigger fault estimator unit to provide suitable reactive power to recover fault drop voltage as illustrated in Figure 3.

Table 1. Offline parameter BDSWRG [8]

\begin{tabular}{ccc}
\hline $\mathrm{S}$ & Value & Definition \\
\hline $\mathrm{fp}$ & 50 & Line Frequency $[\mathrm{Hz}]$ \\
$\mathrm{Vp}$ & 690 & Grid voltage $[\mathrm{V}]$ \\
$\mathrm{Pr}$ & 4 & Rotor poles \\
$\mathrm{J}$ & 3.8 & Total drive shaft inertia $[\mathrm{kgm} 2]$ \\
$\mathrm{Rp}$ & 0.0375 & Resistance of Primary Winding $[\Omega]$ \\
$\mathrm{Rs}$ & 0.0575 & Resistance of Secondary Winding $[\Omega]$ \\
$\mathrm{Lp}$ & 1.17 & Inductance of Primary Winding $[\mathrm{mH}]$ \\
$\mathrm{Ls}$ & 2.89 & Inductance of Secondary Winding $[\mathrm{mH}]$ \\
$\mathrm{Lps}$ & 0.98 & Mutual Inductance $[\mathrm{mH}]$ \\
\hline
\end{tabular}
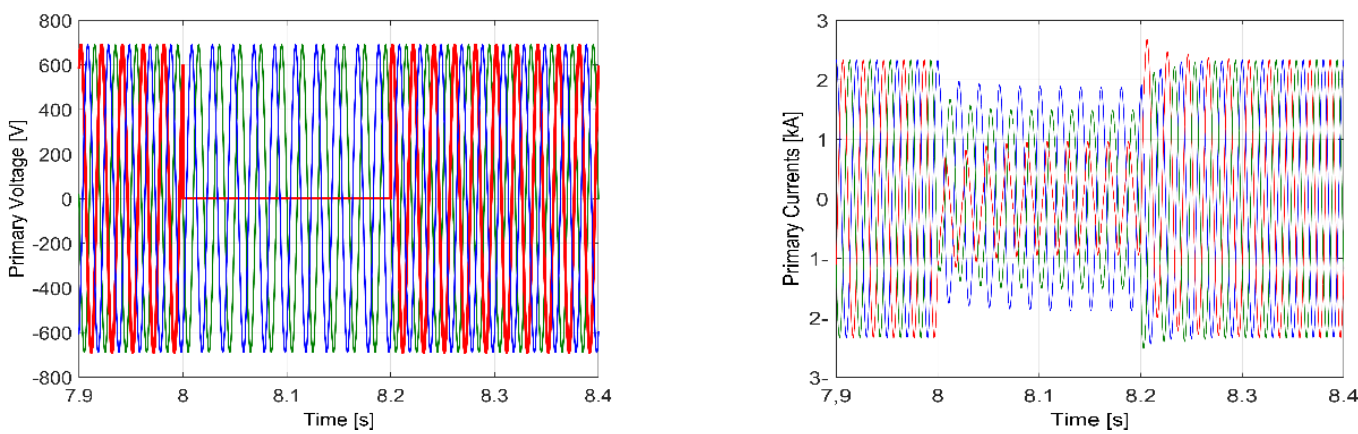

Figure 3. Primary voltages and current under asymmetrical fault

The relics left by such crash appear clearly in the form of uneven sustained repels which described the given crash as a serious fault in the primary parameters Figure 4. The system control follows the desired currents produced from the fault trigger unit as reference currents isd*,isq* Figure 5, satisfying from the PI controller can be achieved the suitable reactive power to recover the fault. The currents isd tuned to zero that decrees the repel effects which are transferred from the primary side to enable the isq to provide reactive power to the secondary side stage during fault period (8-8.2) s, the complete action can be seen in Figure 5 showing the dq secondary current when the isq take the role of the direct current in faulty condition to the clearance asymmetrical fault the isq declare to zero and return to follow the master control in normal condition. One of the facts could be concluded in this study is the range of severity asymmetrical faultless than symmetrical fault so it was easy to recover.
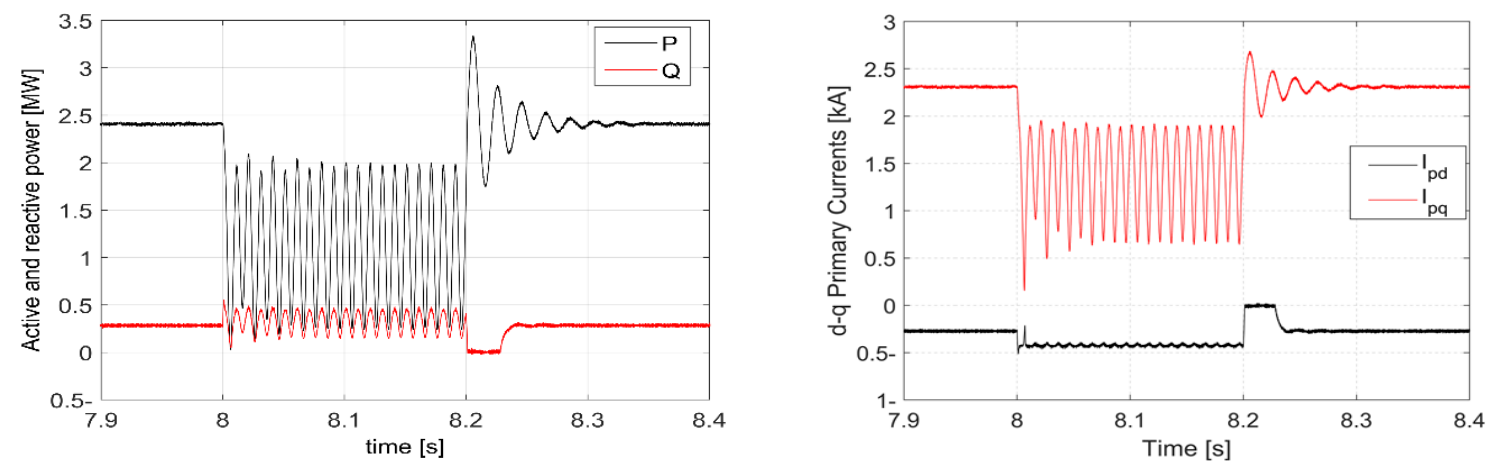

Figure 4. dq primary current and the period asymmetrical fault 

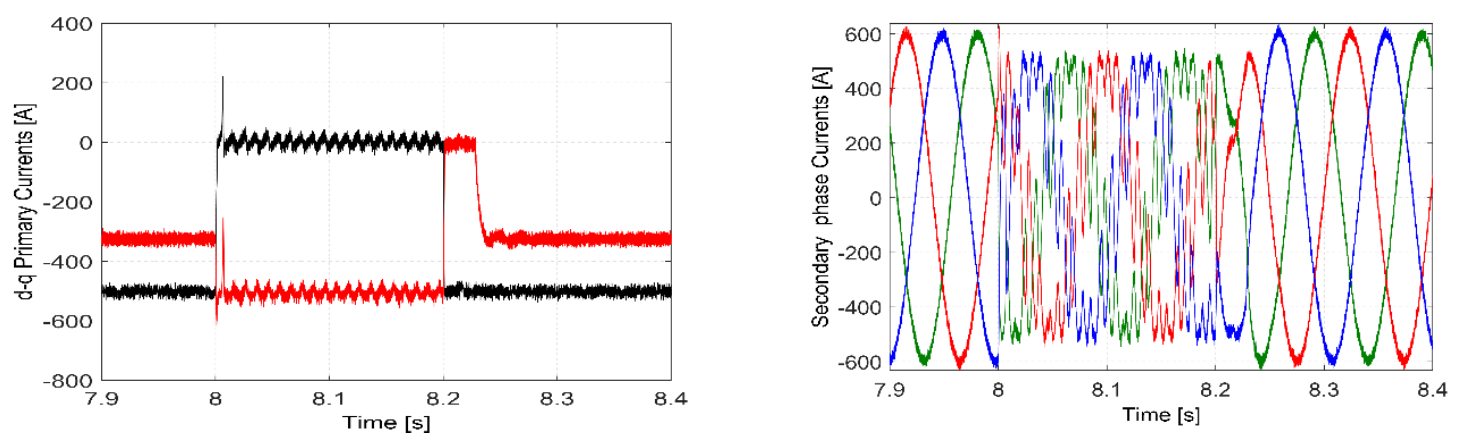

Figure 5. Secondary currents after compensating reactive power

\section{CONCLUSION}

Referring to the extracted results the investigation exceptionally demonstrates the ability of BDSWRG to overcome asymmetric faults, especially when the case is losing one of the three phases of grid voltage (dip voltage). This difference in-phase and a drop in the voltage. Obvious deformation in the magnetic field and voltage profile during the fault period (8-8.2) $\mathrm{ms}$ at the primary side of the machine which is directly faced the drop of voltage especially in the first figures before the reactive power is pumped from the fault and the degree of improvement has been driven by injecting the reactive power from the fault unit in. the following figures. The results confirmed well the capability of FOC control advantages over rest control algorithms to handle drop voltage during the short-term fault period due to the inherited decoupling behavior of the $\mathrm{I}_{\mathrm{d}}-\mathrm{I}_{\mathrm{q}}$ currents and high performance and precision tracking of the change in the desired voltages. The rest of the important outcome from this experimental work is confirming the validation and capability of BDSWRG in manufacture requirements and WECS applications to ride through the asymmetrical fault. The asymmetry of phase tolerance led to the unbalance and fluctuation in magnetic flux and voltage could harm the machine or losing control in offshore plants. So, the adoption of the LVRT requirement will enable the system to recover the drop-in voltage and unwanted glitches and returned the power distribution stability without any interruption between the generators and grid.

\section{REFERENCES}

[1] X. Wei, M. Cheng, W. Wang, P. Han, and R. Luo, "Direct voltage control of dual-stator brushless doubly fed induction generator for stand-alone wind energy conversion systems," IEEE Transactions on Magnetics, vol. 52, no. 7, pp. 1-4, July 2016, Art no. 8203804, doi: 10.1109/TMAG.2016.2526049.

[2] D. K. Bhutto, J. Ahmed Ansari, S. S. Hussain Bukhari, and F. Akhtar Chachar, "Wind energy conversion systems (wecs) generators: a review," 2nd International Conference on Computing, Mathematics and Engineering Technologies (iCoMET), 2019, pp. 1-6, doi: 10.1109/ICOMET.2019.8673429.

[3] A. Memon, M. W. Mustafa, S. K. Baloch, A. Khidrani, and T Ahmed "Dynamic response enhancement of BDFIG using vector control scheme based internal model control," Indonesian Journal of Electrical Engineering and Computer Science, vol. 23, no. 1, pp. 90-97, 2021, doi: 10.11591/ijeecs.v23.i1.pp90-97.

[4] M. Hasan, R. Mejeed, and H. Hameed, "Analysis of diyala power network for the distributed feeders between Iraq and Iran: $132 \mathrm{kV}$ Baquba-Sarbilzahab," International Review of Electrical Engineering (IREE), vol. 14, no. 5, pp. 358-366, doi: doi.org/10.15866/iree.v14i5.17122.

[5] J. A. B. Rodrigo, H. V. Blavi, M. Ayad, and J. I. Talpone, "Low-voltage ride through capability testing of a DWIG for wind power generation," 11th IEEE International Conference on Compatibility, Power Electronics and Power Engineering (CPE-POWERENG), 2017, pp. 582-587, doi: 10.1109/CPE.2017.7915237.

[6] P. Han, M. Cheng, X. Wei, and Y. Jiang, "Steady-state characteristics of the dual-stator brushless doubly fed induction generator," IEEE Transactions on Industrial Electronics, vol. 65, no. 1, pp. 200-210, 2018, doi: 10.1109/TIE.2017.2716904.

[7] H. Mahieddine, L. Zarour, L. Lamri, and N. Ahmed Lokmane, "Developing a grid-connected DFIG strategy for the integration of wind power with harmonic current mitigation," International Journal of Electrical and Computer Engineering IJECE, vol. 9, no. 5, pp. 3905-3915, 2019, doi: 10.11591/ijece.v9i5.pp3905-3915.

[8] A. O. Akinrinde, A. Swanson, and R. Tiako, "Dynamic behavior of wind turbine generator configurations during ferroresonant conditions," Energies, vol. 12, no. 639, pp. 1-16, 2019, doi: 10.3390/en12040639.

[9] A. O. Akinrinde, A. Swanson, and R. Tiako, "Effect of ferroresonance on wind turbine: comparison of ATP/EMTP and matlab/simulink," Indonesian Journal of Electrical Engineering and Computer Science, vol. 14, no. 3, pp. 1581-1594, 2019, doi: 10.11591/ijeecs.v14.i3.pp1581-1594. 
[10] T. Ouchbel, S. Zouggar, M. L. Elhafyani, M. Mokhtari, M. Oukili, and F. Zahra Kadda, "Control of a variable speed asynchronous wind turbine dedicated to isolated site," Indonesian Journal of Electrical Engineering and Computer Science, vol. 20, no. 2, pp. 627-637, 2020, doi: 10.11591/ijeecs.v20.i2.pp627-637.

[11] A. O. Akinrinde, A. Swanson, and R. Tiako, "Investigation and analysis of temporary overvoltages caused by filter banks at onshore wind farm substation," International Journal of Renewable Energy Research, vol. 7, no. 2, pp. 770-777, 2017.

[12] M. A. Mahboub, S. Drid, M, A. Sid, and R. Cheikh, "Sliding mode control of grid connected brushless doubly fed induction generator driven by wind turbine in variable speed," International Journal of System Assurance Engineering and Management, vol. 8, pp. 788-798, 2017.

[13] M. Jovanović, and H. Chaal, "Wind power applications of doubly-fed reluctance generators with parameter-free hysteresis control," Energy Conversion and Management, vol. 134, pp. 399-409, 2017, doi: 10.1016/j.enconman.2016.10.064.

[14] M. N. F. Nashed, M. N. Eskander, and M. A. Saleh, "Mitigation of faults in grid-connected wind-driven single machine brushless double-fed induction generator," Indonesian Journal of Electrical Engineering and Computer Science, vol. 15, no. 3, pp. 1178-1188, 2019, doi: 10.11591/ijeecs.v15.i3.pp1178-1188.

[15] A. Oraee, E. Abdi, and R. McMahon, "Converter rating optimization for a brushless doubly fed induction generator," IET Renew. Power Gener., vol. 9, no. 4, pp. 360-367, 2015, doi: 10.1049/iet-rpg.2014.0249.

[16] X. Wang, H. Lin, and Z. Wang, "Transient control of the reactive current for the line-side converter of the brushless doubly-fed induction generator in stand-alone operation," IEEE Transactions on Power Electronics, vol. 32, no. 10, pp. 8193-8203, Oct. 2017, doi: 10.1109/TPEL.2016.2609461.

[17] M. Hasan, R. Abd, and R. Ali, "Enhancement Mathematical model of IM drive using rotation coordinate for better output performance," International Journal of Mechanical Engineering and Technology IJMET, vol. 9, no. 9, pp. 851-865, 2018.

[18] F. Bu, H. Liu, W. Huang, H. Xu, and Y. Hu, "Recent advances and developments in dual stator-winding induction generator and system," IEEE Transactions on Energy Conversion, vol. 33, no. 3, pp. 1431-1442, 2018, doi: 10.1109/TEC.2018.2796610.

[19] M. Rihan, M. Nasrallah, and B. Hasanin, "Performance analysis of grid-integrated brushless doubly fed reluctance generator-based wind turbine: modelling, control and simulation," Springer Nature Switzerland, vol. 2, no. 114, pp.1-9, 2019, doi: 10.1007/s42452-019-1907-0.

[20] S. Ademi, M. G. Jovanović, H. Chaal, and W. Cao, "A new sensorless speed control scheme for doubly fed reluctance generators," IEEE Transactions on Energy Conversion, vol. 31, no. 3, pp. 993-1001, 2016, doi: 10.1109/TEC.2016.2533609.

[21] I. Ngom, A. B. Mboup, and L. Thiaw, "Active and reactive power control of doubly fed-induction generator based on variable speed wind power generation," DEStech Transactions on Engineering and Technology Research, vol. 27, no. 1, pp. 113-121, 2018, doi: 10.12783/dtetr/ecar2018/26309.

[22] M. I. Abdelkader, A. K. Abdelsalam, and A. A. Hossameldin, "Indirect vector-controlled brushless doubly-fed twin-stator induction generator for wind energy conversion application," Energies journal, vol. 13, no. 16, pp. 4174-4190, 2020, doi: 10.3390/en13164174.

[23] A. Loulijat, N. Ababssi, and M. Makhad, "DFIG use with combined strategy in case of failure of wind farm," International Journal of Electrical and Computer Engineering IJECE, vol. 10, no. 3, pp. 2221-2234, 2020, doi: 10.11591/ijece.v10i3.pp2221-2234.

[24] H. Chaal, and M. Jovanovic, "Practical implementation of sensorless torque and reactive power control of doubly fed machines," IEEE Transactions on Industrial Electronics, vol. 59, no. 6, pp. 2645-2653, 2012, doi: 10.1109/TIE.2011.2161065.

[25] A. Benamor, M. T. Benchouia, K. Srairi, and M. E. H. Benbouzid, "A novel rooted tree optimization applies in the high order sliding mode control using super-twisting algorithm based on DTC scheme for DFIG," International Journal of Electrical Power \& Energy Systems, vol. 108, pp. 293-302, 2019, doi: 10.1016/j.ij.epes.2019.01.009

[26] C. A. Evangelista, A. Pisano, P. Puleston, and E. Usai, "Receding horizon adaptive second-order sliding mode control for doubly-fed induction generator based wind turbine," IEEE Transactions on Control Systems Technology, vol. 25, no. 1, pp. 73-84, 2017, doi: 10.1109/TCST.2016.2540539.

[27] M. Bouderbala, B. Bossoufi, A. Lagrioui, M. Taoussi, H. Alami Aroussi, and Y. Ihedrane, "Direct and indirect vector control of a doubly fed induction generator based in a wind energy conversion system," International Journal of Power Electronics and Drive Systems IJPEDS, vol. 9, no. 3, pp. 1531-1540, 2019, doi: 10.11591/ijece.v9i3.pp1531-1540.

[28] M. S. Hasan, G. A. Salman, and H. I. Hussein, "Prototype of implementation SVPWM inverter in RTIwith V/F control based reluctance machines application," International Review of Electrical Engineering, vol. 13, no. 3, pp. 510-522, 2018, doi: 10.15866/iree.v13i3.14738.

[29] M. S. Nazir, Q. Wu, M. Li, and L. Zhang, "Symmetrical short circuit parameter differences of double fed induction generator and synchronous generator based wind turbine," International Journal of Power Electronics and Drive Systems IJPEDS, vol. 6, no. 2, pp. 268-277, 2017, doi: 10.11591/ijeecs.v6.i2.pp268-277.

[30] H. A. Aroussi, E. Ziani, M. Bouderbala, and B. Bossoufi, "Enhancement of the direct power control applied to DFIG-WECS," International Journal of Electrical and Computer Engineering IJECE, vol. 10, no. 1, pp. 35-46, 2020, doi: 10.11591/ijece.v10i1.pp35-46. 


\section{BIOGRAPHIES OF AUTHORS}
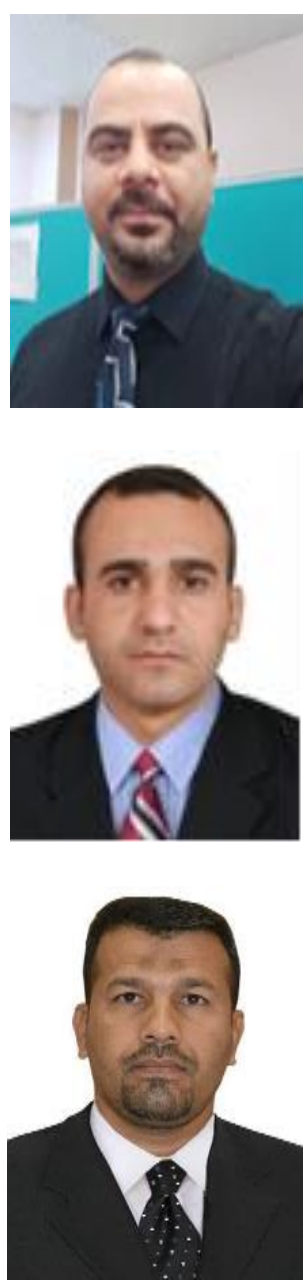

Qasim Al Azze has obtained a Master Degree of Electrical Engineering, in 2014, in area of Electrical Power and Control Machines Engineering from SIUE, USA. In 2005, he resived a Bachelor of Science in Electrical Power and Machines Engineering from college of Engineering University of Diyala, Iraq. At present, he is lecturer at Electrical Power \& Machines Depart. University of Diyala. He teachs Electrical Machines and Drives Course and its LAB, at Dep. of Electrical Power and Machines. Previously, graduated projects in the department. His interesting area are Power System, Power Electronics, Electrical Drives Machine, Renewable Energy, Smart Grid, and Electric Vehicles.

Balasim M. Hussein received a PhD from Russian South State University (Russia), in 2015. In 2008, he obtained Msc degree from University of Technology, Iraq, in Electrical Power field. In 2004, he obtaind Bachelor of Science in Electrical Power and Machine from Univeristy of Diyala. Presently, he is a lecturer at the Department of Electrical Power \& Machine Engineering at University of Diyala. His area of research interesting are Power system, Power system Stability, Power Generation, power system operation and control. He has published several research papers several journals including Science Direct, Electromechanical Journal, Modern Problems in a Science Journal, measurement and control journal and International Journal of Electrical and Computer Engineering.

Hayder Salim Hameed received his bachelor's degree from Diyala University, College of Engineering, Department of Power and Electrical Machines Engineering in 2002, and he obtained a master's degree from the University of Baghdad in Electrical Engineering / Power and Electrical Machines in 2014. Currently he is a lecturer in the Department of Power and Electrical Machines Engineering, with practical experience in the field of electrical engineering. His research interests focus on electrical power systems, electrical machines and their control, power electronics and their control through FPGAs. (Email: alskooki@gmail.com) 